\title{
Once or Twice a Week
}

National Cancer Institute

\section{Source}

National Cancer Institute. Once or Twice a Week. NCI Thesaurus. Code C121632.

An indication that something occurs or occurred once or twice a week. 